\title{
Num Universo Aberto e Dinâmico
}

\section{A singularidade dos processos irreversíveis}

A natureza aleatória inerente aos fenómenos do mundo quântico, e o tratamento estatístico que implica confere a tais fenómenos um carácter de imanente irreversibilidade. Esta é uma propriedade física objectiva dos sistemas aleatórios, e não mera degradação de informação disponível para o observador, mercê da complexidade crescente do sistema exibindo comportamento aleatório, como o pretende a chamada interpretação subjectivista da irreversibilidade. E uma irreversibilidade intrínseca aos processos e não mera irreversibilidade «epistemológica». O carácter aleatório do fenómeno quântico implica necessariamente a sua irreversibilidade objectiva.

O universo estático da mecânica clássica de Newton era susceptível de uma descrição fundamental precisa em termos de trajectórias deterministas. Bastaria conhecer a lei geral da trajectória que determina a passagem do sistema entre dois estados instantâneos sucessivos, quaisquer que sejam, e o conhecimento de um determinado estado instantâneo do sistema, a partir do qual a aplicação daquela lei permitirá o cálculo da trajectória, de estado em estado, tanto para o passado como para o futuro. A lei da dinâmica de Newton é uma lei reversível: descreve com a mesma precisão a passagem de um estado para o imediatamente precedente como para o imediatamente seguinte. A situação é diferente no universo aberto e dinâmico da mecânica quântica confrontada com o acaso que informa o próprio interior da matéria [1]. Substituindo a noção de trajectória por uma função de onda para descrever o movimento das partículas quânticas, em termos de probabilidade, a mecânica quântica não teve quaisquer problemas com a afirmação da reversibilidade do movimento assim descrito; tal como na mecânica clássica, também aqui o presente implica, o futuro e o passado. Mas cedo deparou com o problema da irreversibilidade do crescimento do caos molecular, o crescimento entrópico associado aos processos a que se chega por flutuações onde a actividade produz a novidade e a evolução é criação e destruição, nascimento e morte, em inovação para um mundo de que se não pode regressar pelo mesmo caminho. No equilíbrio, ou próximo dele, os sistemas formados por processos determinados evolutivamente por flutuações são também eles estáveis; porém, para além do limiar dessa estabilidade, são susceptíveis de comportamentos qualitativamente diversos, dependentes de transformaçôes dissipativas que neles possam ter ocorrido e condicionados pelo próprio passado do sistema. Consequentemente, o estado de equilíbrio ou esta- cionário em que se encontram não é um estado puramente instantâneo, implicando, sim, as bifurcações sucessivas que tenha atravessado, onde o determinismo dinâmico dá lugar à dialéctica complexa entre acaso e necessidade. Impōe-se, então, descrever não só o estado de equilíbrio ou o estado estacionário em que o sistema se encontra, como também a evolução do mesmo para esse estado.

O estado de equilíbrio termodinâmico é atingido quando se verifica a chamada distribuição de Boltzmann-Maxwell, traduzida por uma «curva em sino» que, nos trabalhos de Laplace, Gauss e Quételet, é tratada como sendo a própria expressão do acaso. A descrição da evolução física do sistema para o estado de equilíbrio depara com a análise do próprio mecanismo molecular, e com ele a evolução da entropia do sistema que por sua própria natureza, não se pode processar ao nível de trajectórias individuais das moléculas, mas tão somente ao nível duma população de moléculas, tratada estatisticamente por uma função de distribuição média. Neste tratamento estatístico se empenhou, em particular, Boltzmann, analisando o movimento contínuo das partículas, consideradas como independentes, e as colisões entre elas. No seu estudo, Boltzmann mostrou que a grandeza $\mathrm{H}=\mathrm{f}(\mathrm{v}, \mathrm{t})$ $\log \mathrm{f}(\mathrm{v}, \mathrm{t}) \mathrm{dv}$, onde $\mathrm{f}(\mathrm{v}, \mathrm{t})$ é a função que descreve o efeito das colisões das partículas na sua posição e velocidade de equilíbrio, não podia senão diminuir no decurso do tempo até atingir um mínimo no instante em que $\mathrm{f}(\mathrm{v}, \mathrm{t})$ corresponde à distribuição de Maxwell-Boltzmann de equilíbrio. Essa grandeza tornava-se assim a chave do estudo da evolução molecular e da interpretação microscópica da variação da entropia. Tal grandeza constitui o que se pode chamar um atraente universal: dependente apenas da função de distribuição das velocidades, o seu conhecimento permite saber como o sistema se afastou do estado atraente, o estado de equilíbrio.

Relacionando-a com a entropia do sistema, isto é, com o seu grau de desordem molecular, Boltzmann definiu $\mathrm{S}=-\mathrm{K} \mathrm{H}$, onde $\mathrm{K}$ é a constante universal de Boltzmann.

Do ponto de vista conceptual, o tratamento de Boltzmann leva à clara distinção entre fenómenos reversíveis e fenómenos irreversíveis: na evolução dos sistemas moleculares, o movimento contínuo das partículas consideradas como independentes é um processo reversível, enquanto que as colisões entre partículas é um processo irreversível.

Aleatório em si mesmo, dado a caos molecular em que se

\footnotetext{
Departamento de Química, Universidade 3000 Coimbra - Portugal
} 
gera, o processo de colisões pressupõe que antes de cada colisão as diferentes moléculas têm comportamentos independentes uns dos outros; consequentemente, tal processo não pode ser reversível já que a sua inversão só seria possível em termos de um sistema altamente organizado, de comportamento totalmente pré-determinado, com a absoluta negação de toda a independência do comportamento molecular antes de cada colisão, isto é, com absoluta negação do próprio carácter aleatório do processo. A natureza estatística de um qualquer processo é de todo incompatível com a sua reversibilidade.

Dizer que na evolução de um sistema para o seu estado de equilíbrio, o estado atraente ou o estado estacionário, $\mathrm{H}$ não pode senão diminuir no decurso do tempo até atingir um mínimo no momento em que $\mathrm{f}(\mathrm{v}, \mathrm{t})$ corresponde à distribuição de Maxwell - Boltzmann no equilíbrio, e a associação de H com a entropia do sistema, separável do efeito reversível do movimento contínuo das partículas consideradas como independentes, é dizer que num processo reversível, a entropia do universo é constante, e num processo irreversível a entropia do universo aumenta. Esta é uma das formulações possíveis do II Princípio da Termodinâmica. Esta formulação associa de imediato o II Princípio da Termodinâmica o significado com a flecha do tempo no seio da natureza, como iremos notar mais adiante [2].

A variação da entropia dS na evolução de um qualquer sistema termodinâmico pode sempre escrever-se como a soma de dois termos: um termo dSe ligado às trocas entre o sistema e o resto do mundo, e um termo dSi correspondente aos fenómenos irreversíveis que ocorram dentro do próprio sistema, isto é, $\mathbf{d S}=\mathbf{d S e}+\mathbf{d S i}$.

Para sistemas energeticamente isolados, $\mathbf{d S e}=\mathbf{0}$; e fora do estado de equilíbrio o termo dSi é sempre positivo, tornandose nulo no equilíbrio; quer dizer, dSi é sempre positivo ou nulo. Para um sistema isolado tem-se, pois, que dS é também sempre positivo ou nulo, o que significa que para um sistema isolado a entropia nunca diminui: é nula no equilíbrio; aumenta, fora do equilíbrio. Esta é uma outra formulação possível do II Princípio da Termodinâmica.

Num sistema aberto, em evolução para o equilíbrio, a variação da entropia tanto poderá ser positiva, como negativa, de acordo com o balanço entre o termo dSi e o termo dSe. Nas trocas com o exterior, $\mathbf{d S e}$ será negativo se o sistema estiver aberto para um mundo mais frio; e será positivo, no caso contrário.

O facto de a entropia, num sistema aberto, poder decrescer não põe em causa o II Princípio da Termodinâmica pois que a variação da entropia a que este se refere é a do termo $\mathbf{d S i}$, ou seja, a própria produção de entropia no interior do sistema durante a sua evolução para o equilíbrio: nula, se a evolução é reversível; positiva, se a evolução é irreversível. Quer dizer, para melhor compreendermos o sentido físico do II Princípio da Termodinâmica o que se impõe é analisar o modo como a própria reversibilidade ou irreversibilidade de um processo evolutivo se relaciona com a produção de entropia.

Sirva-nos, para o efeito, de exemplo, os processos químicos que envolvem uma reacção química, pelo papel fundamental que desempenham em toda a natureza e, em particular, no domínio da biologia, pois que a célula viva é sede de uma actividade metabólica incessante e altamente ordenada, quer do ponto de vista da coordenação das diferentes velocidades de reaç̧ão, quer do ponto de vista da sua localização na célula, onde milhares de reacções químicas simultâneas transformam a matéria de que a célula se nutre, sintetizam os seus constituintes e lançam para o exterior os produtos não utilizáveis [3].

Tais reacções constituem o exemplo-tipo de processos cujo «início» e «fim» escapam às teorias da física reversível: a mecânica quântica pode certamente descrever as propriedades de estabilidade das diferentes moléculas, mas não pode descrever a dimensão irreversível do processo no decurso do qual duas ou mais moléculas interaccionam entre si e se transformam. Um sistema sede de reacções químicas, quando entregue a si mesmo, evolui para um estado de equilíbrio químico, equilíbrio este que constitui o próprio exemplo de estado atractivo pois que qualquer que seja a sua composição química inicial, o sistema evolui espontaneamente para tal estado, caracterizado por concentrações químicas definidas pela lei de acção das massas (lei de Guldberg e Waage) que não depende senão da natureza dos reagentes e de parâmetros termodinâmicos. A velocidade com que essa evolução se processa é definida pela sua cinética que envolve as concentrações dos diversos reagentes e diversos outros factores, podendo compreender não só certas variáveis termodinâmicas como até a presença no sistema de substâncias modificadoras do mecanismo reactivo, os chamados catalisadores de reacção.

O sentido da reacçãoé determinado por uma «força química», a afinidade, cuja acção é idêntica à do gradiente de temperatura que determina o sentido de um fluxo de calor. A afinidade não só indica o sentido da reacção, como mede a distância do sistema em relação ao equilíbrio: o seu valor absoluto é tanto maior quanto mais o sistema se encontra distante do equilíbrio; e é nulo quando o sistema atingiu o equilíbrio. No equilíbrio a produção de entropia é nula; no domínio próximo do equilíbrio, a produção de entropia varia linearmente com o valor da afinidade; no domínio longe do equilíbrio, a produção de entropia é uma função não-linear da afinidade.

As célebres «relações de reciprocidade» propostas por Onsager, em 1931 [4], mostram que um sistema, no domínio próximo do equilíbrio, evolui para este pela produção de entropia mínima compatível com as coerções impostas ao sistema. A actividade irreversível do sistema não impede que a sua evolução se dê para um estado inteiramente dedutível a partir de leis gerais [5].

\section{A evolução da vida}

A evolução da vida insere-se no ciclo da evolução do próprio universo. Dominada por todo um conjunto de processos irreversíveis, ela mostra, todavia, uma tendência geral para se afastar da desordem boltzmanniana, contrariando o aumento contínuo da entropia característica da evolução irreversível de um sistema fechado. De facto, a evolução da vida traduz-se na aparição de formas naturais cada vez mais organizadas, no seio de um mundo físico cuja tendência geral é para uma crescente desorganização.

Quer dizer, a evolução da vida torna-se incompreensível, e 
mesmo paradoxal, no quadro estrito de um sistema fechado a evoluir necessariamente para a desordem total de acordo com o princípio cósmico traduzido pelo II Princípio da Termodinâmica. Todavia, como sistema aberto, o universo tomado na sua globalidade não é um universo votado a um fim de desordem total. E como ele, também qualquer sistema vivo, e mesmo a Terra inteira, com a sua fauna e a sua flora em desenvolvimento e em crescimento, não são sistemas fechados. A sua evolução através de formas cada vez mais organizadas, não é, de modo algum, incompatível com a evolução por processos irreversíveis, e é também ela um processo evolutivo marcado pela irreversibilidade.

$\mathrm{Na}$ análise termodinâmica da produção não-linear de entropia em função da «força» que está na sua origem, em sistemas abertos, num estado longe do equilíbrio, reside a melhor e mais actual aproximação à compreensão da evolução da vida no universo [6].

Mostra essa análise que sistemas abertos longe do estado estacionário não são informados por uma tendência generalizada para um aumento de desordem, podendo, todavia, produzir entropia que «exportam» para o meio ambiente enquanto aumentam, em vez de diminuir, a sua ordem interna. Longe do equilibrio, esses sistemas podem desenvolver propriedades estruturais e, através disso, fazer exactamente o contrário de passar a um estado de equilíbrio em que já nada de entusiasmante lhes pode acontecer. As flutuações que ocorrem no sistema não regridem necessariamente no sentido do estado estacionário, com a produção de um mínimo de entropia; em vez de regredirem, podem amplificar-se na sequência de pequenos desvios ou perturbações. A sua amplificação pode traduzir-se na edificação de novas estruturas, as chamadas estruturas dissipativas consideradas por Prigogine, cujo nome, de acordo com o mesmo Prigogine, pretende caracterizá-las como uma associação entre a ideia de ordem e a de desperdício. Longe do equilíbrio, os fluxos irreversíveis que atravessam certos sistemas físicos e químicos e os afastam do equilíbrio podem nutrir e criar fenómenos de auto-organização espontânea, com rupturas de simetria e edificação de formas de organização supermolecular, as estruturas dissipativas em que a dissipação de energia e de matéria, geralmente associada às ideias de perda de rendimento e de evolução para a desordem, se torna fonte de ordem. Longe do equilíbrio, a matéria é sensível a influências às quais era surda enquanto em equilíbrio; tornase, em particular, sensível ao ruído que em equilíbrio, não teria nenhuma consequência observável [7].

Nas estruturas dissipativas se afirma e manifesta a indeterminação das evoluções físicas microscópicas. Num ponto de bifurcação, aberto a várias possibilidades de evolução, com características de um processo turbulento, a evolução real do sistema, liberto ainda da acção determinante do atraente universal, por se encontrar ainda longe do estado de equilíbrio, dependerá da natureza da flutuação que vier efectivamente a desestabilizá-lo. Da sua amplificação resultará o seu estado macroscópico efectivo. Num universo em expansão, capaz de manter certos sistemas longe do equilíbrio, a evolução dominada por processos aleatórios portadores de entropia, defronta-se continuamente com posições de bifurcação que podem dar origem à desordem ou à formação de estruturas dissipativas em que é gasta energia do meio para criar complexidade e ordem. Neste processo turbulento de evolução se torna compreensível a evolução da própria vida, onde a complexidade e a ordem não param de crescer, e onde o devir aparece como condição do ser.

A desordem está presente em toda a parte; ela está na energia (calor), como está no tecido sub-atómico e na origem do nosso universo. Todavia, na evolução turbulenta do universo, em bifurcações que continuamente surgem, ela pode cooperar «estranhamente» com a própria ordem para criar mais organização, mais complexidade. Em encontros aleatórios com elevado grau de desordem se geraram as altamente ordenadas organizações físicas que são o núcleo, o átomo, os astros e o ser vivo. Tal como a ordem, também o caos faz parte da estrutura do universo em que vivemos [8].

Segundo Monod [9], a vida teria emergido da matéria inanimada por uma combinação extremamente improvável de circunstâncias aleatórias, sendo mesmo possível que se trate de um acontecimento único, isto é, um acontecimento cuja probabilidade não seria simplesmente baixa, mas sim de tal modo próxima do zero que do ponto de vista prático, pode ser considerada nula, na melhor das aproximações. Monod baseia esta sua hipótese do carácter único da origem da vida no carácter único do código genético: são inúmeras as combinações que podiam dar origem a uma proteína, mas muitíssimo poucas as correctas para obter o código genético.

Todavia, de acordo com o que ficou dito, sabe-se, hoje, que em situações longe do equilíbrio, certos fenómenos pouco prováveis podem ocorrer com grande facilidade. Na Natureza há inúmeras bifurcações onde o inesperado e não-previsível ocorre com facilidade. De qualquer modo, pouco provável ou não, a vida apareceu no universo que, provavelmente não teria sentido sem ela. E uma vez ocorrido o seu aparecimento, evoluiu continuamente, no decurso de milhões e milhões de anos, para formas altamente organizadas e cada vez mais estruturadas, num contínuo processo de autoorganização que comporta um processo permanente de desorganização e re-organização, termodinamicamente explicável em termos de um universo não-fechado, longe do estado de equilíbrio. Um universo fechado e determinado por um estado estacionário calor, no caos molecular total, onde a vida seria algo profundamente estranho, misterioso e precário. Temos, todavia, razões para crer que essa não seja necessariamente a sorte fatídica do universo em que vivemos.

\section{A fenomenologia do tempo}

No universo determinista da física clássica, o tempo mais não é que um fluir absolutamente homogéneo a que não é possível assinalar uma direç̧ão: prever o movimento futuro de um pêndulo ou descrever o seu movimento passado reduzse a um e mesmo problema matemático. $\mathrm{O}$ mesmo não acontece no mundo indeterminista dos fenómenos quânticos e no quadro de uma cosmologia relativista. $\mathrm{O}$ indeterminismo subjacente aos fenómenos da Natureza obriga-nos a repensar toda a fenomenologia do tempo.

Num universo em evolução em que, por processos turbulentos, longe do equilíbrio, em que a desordem através de estruturas instáveis de não-equilíbrio se pode tornar fonte de ordem, o devir irreversível define o sentido da flecha do 
tempo e «impōe-se como novo pensamento da eternidade», no dizer de Prigogine no seu livro Physique, Temps et Devenir [6b]. Segundo o mesmo autor, «o universo é uma temporalidade e o tempo é a sua coerência» [10]. O tempo integra o homem no universo.

O ser e o devir foram sempre para os filósofos e cientistas empenhados na procura da compreensão do universo, os termos de uma dicotomia de difícil conciliação. Reduzir o diverso e a mudança ao idêntico e permanente seria eliminar o tempo e refugiar-se na eternidade. Não têm sido poucos os filósofos e cientistas que desde o primeiro instante do despertar da atitude teorética se têm deixado levar pela ambição de conseguir este refúgio na eternidade, a ponto de afirmarem que a distinção entre passado, presente e futuro mais não é que simples ilusão, ainda que tenaz. Einstein foi um desses cientistas [11].

Para além de todas as discussões filosóficas, à ciência não é, contudo, possível eliminar o tempo, se não mais fora, pelo menos como aquele parâmetro geométrico de que falaram os Enciclopedistas do século XVIII que permite contar do exterior e, como tal, esgota a verdade do devir de todo o ser natural.

A física dos nossos dias, a braços com processos irreversíveis, como a difusão de dois líquidos ou as reacções químicas, reconhece que o tempo não só tem um sentido, como reconhece também que esse sentido desempenha um papel essencial na evolução do universo.

A nossa própria experiência interior, marcada profundamente pela dimensão aleatória e imprevisível que tantas vezes informa as mais variadas das nossas acções, particularmente no domínio da criação intelectual, mostra que o problema do tempo não é tão linear quanto o afirmou a mecânica clássica. Hoje, a Física reconhece que cada ser complexo é constituído por uma pluralidade de tempos, desde o chamado tempo de recorrência de Poincaré ao tempo de Liapounov, medido pelo afastamento das trajectórias, ou, de acordo com S. Hawking, duma solução determinista para a criação do universo, a supressão da diferença entre tempo e espaço [15]. O tempo não pode ser de forma alguma uma ilusão; é algo que está bem enraizado na natureza, por mais que não sejamos capazes de o definir ou apreender, a todos nós acontecendo o que acontecia a Santo Agostinho que interrogado sobre o que pudesse ser o tempo respondia a si próprio: «se ninguém mo perguntar, sei muito bem o que é; porém, se quero explicá-lo a quem me interroga, já não sei» [12].

De facto, a evolução do universo dá-se no tempo, com um passado, um presente (que mais não é que um instante, e apesar de tudo o único realmente existente!) e um futuro, definindo a flecha ou seta do tempo. Afirmar uma evolução baseada em fenómenos irreversíveis, sem retorno, é correlativamente afirmar a irreversibilidade desta flecha [13].

$\mathrm{O}$ passado, aquilo que aconteceu, não pode ser mudado. Nesse sentido se pode dizer que ele é completamente determinado, isto é, causalmente fechado. Outro tanto não parece poder dizer-se do futuro que embora determinado pelo seu passado está, em cada instante presente, aberto à influência de processos aleatórios. Deste ponto de vista, há uma assimetria indestrutível entre o passado e o futuro; ao carácter fechado do passado contrapõe-se a abertura do futuro.
Em termos físicos, esta assimetria traduz-se na possibilidade de uma qualquer cadeia causal física, a partir de um qualquer lugar no passado poder alcançar qualquer lugar no futuro, enquanto que a partir de lugar nenhum do futuro poderá semelhante efeito ser exercido sobre qualquer lugar do passado [14].

Aberto, o futuro não pode ser plenamente conhecido de antemão, independentemente da capacidade cognoscistiva do agente que sobre ele se debruce; a sua imprevisibilidade plena, tal como a irreversibilidade e o indeterminismo de que já falámos, é uma imprevisibilidade intrínseca e não meramente epistemológica.

A própria Teoria da Relatividade Restrita, com o seu duplo cone tetradimensional do tempo leva facilmente à conclusão que qualquer acontecimento acerca do qual se possa ter alguma informação completa é um acontecimento pertencente ao passado. Só o passado, região fechada para o presente, pode ser conhecido com precisão; o futuro, região aberta à influência do presente do «aqui e agora» e do presente-futuro, não só é desconhecido, como não é, em princípio, plenamente cognoscível; ao tornar-se plenamente conhecido passaria a fazer parte do passado de quem o conheceu.

A assimetria entre o passado e o futuro define, pois, um sentido para a flecha do tempo. Eddington (1882-1944) defendeu que esse sentido seria sempre o determinado pela evolução da entropia do universo; o II Princípio da Termodinâmica seria a sua melhor e natural expressão. Dizer que a desordem aumenta com o tempo é o mesmo que dizer que medimos o tempo no sentido em que a desordem aumenta [15]. E podemos dizer que o é, de facto, para sistemas em equilíbrio ou próximos do estado de equilíbrio. Não, porém, necessariamente, para sistemas longe do equilíbrio em que a evolução da entropia só por si não chega para definir o sentido da seta do tempo. Para estes, torna-se necessário entrar em linha de conta com as bifurcações atravessadas pelo sistema, as estruturas de não-equilíbrio, e a sucessão das flutuações que decidiram da história real do sistema, isto é, que definiram o sentido real do seu tempo, de entre as múltiplas histórias possíveis.

A evolução da seta do tempo num universo em que o processo evolutivo da energia e da matéria é marcado por uma ordem por flutuaçâo não pode ser meramente descrita pela evolução da entropia; implica o recurso a conceitos que até aqui pareciam reservados aos fenómenos biológicos, sociais e culturais, nomeadamente, as noções de história, de estrutura e de actividade funcional [16].

As leis macroscópicas universais descrevem a evolução do universo para a desordem, para os estados de equilíbrio ou estacionários próximos dele. O II Princípio da Termodinâmica é o seu enquadramento natural. O tempo em que se desenvolvem tem o sentido da evolução da entropia do universo. Porém, tais leis não constituem o contexto em relação ao qual tudo no universo possa ser definido. Escapalhes o mundo quântico, como lhes escapa toda a evolução que ocorra longe do equilíbrio, por flutuações dissipativas, onde as consequências do crescimento da entropia não podem ser interpretadas segundo o princípio de ordem de Boltzmann, posto que em tais circunstâncias, os processos produtores de entropia, os processos que dissipam energia, podem desempenhar um papel construtivo. Aqui, a ideia de lei universal 
cede o lugar à de exploração de estabilidades e instabilidades singulares; e a oposição entre o acaso das configurações iniciais particulares e a generalidade previsível da evolução que determinam dá lugar à coexistência de zonas de bifurcação e de zonas de estabilidade, à dialéctica das flutuações incontroláveis e das leis médias probabilísticas.

O processo evolutivo do universo em que vivemos está fortemente marcado por este domínio; nele se situa muito particularmente, a evolução do homem. Na sua singularidade, ele não era certamente, nem chamado, nem esperado pelo mundo. Todavia, com a evolução da vida para estados cada vez mais complexos, $\mathrm{o}$ aparecimento do homem e o seu contínuo progresso para estados cada vez mais evoluídos constituem um fenómeno de algum modo tão «natural» quanto a naturalidade da queda dos graves [10]. O Homem situa-se no seio desta «naturalidade» e a sua posição de topo no processo evolutivo da vida, em que o grau de autoorganização que atingiu the conferiu a possibilidade de assumir plenamente as suas finalidades, poder de que não dispõe nenhuma outra sociedade animal conhecida, conferelhe inegável lugar de relevo no universo que habita [17]. A sua simples presença neste universo dinâmico e aberto, sujeito a um processo evolutivo contínuo a partir de um certo estado inicial cujas características desconhecemos, é dado imprescindível e de suma importância para a possível caracterização do mesmo.

Da evolução possível do universo, a partir do seu estado inicial, dada a indeterminação e a irreversibilidade inerente a muitas das etapas por que passou e aos muitos pontos de bifurcação que atravessou, poderia ter resultado um universo inteiramente diferente do universo que hoje temos. Neste, a forma de vida inteligente que é o homem tornou-se possível e aconteceu.

Este universo aberto e dinâmico em que vivemos não tem por centro a Terra (princípio de Copérnico), e nele a posição do observador-homem não é de modo algum uma posição privilegiada relativamente a quaisquer outras posições de observação; em cosmologia, são de igual modo válidas as observações de observadores situados na Terra, como as observações de observadores colocados em qualquer outro ponto do sistema solar ou em qualquer outra posição do universo, por mais remota que o seja; todos os observadores situados no universo estão numa posição absolutamente equivalente, com igual capacidade para observar os mesmos fenómenos e recolher, por toda a parte, as mesmas informações, isto é, o universo é isotrópico e homogéneo (princípio cosmológico). Todavia, porque «in-formou» a evolução real deste universo, posto que esta foi tal que tornou viável o seu aparecimento, o Homem é em si-mesmo e ipso-facto ponto de referência, de explicação e de compreensão da sua história real (princípio antrópico) [18].

Essa «in-formação» não tem, todavia, um carácter necessário nem exclusivo. Fenomenologicamente, aconteceu. É a história real que os acontecimentos decidiram de entre outras histórias possíveis, à partida. E os nossos conhecimentos actuais estão longe de nos permitirem concluir que seja toda a história do universo.

\section{Referências}

[1] I. Prigogine e I. Stengers, A Nova Aliança, Ed. Gradiva, Lisboa, 1987, Col. Ciência Aberta, 14, pp. 275-277

[2] Ibidem, pp. 279-282; pg. 294

[3] Ibidem, pp. 206ss.

[4] Num processo de difusão de calor e/ou matéria, as equações de movimento dos respectivos fluxos $\mathrm{J}_{1}$ e $\mathrm{J}_{2}$ podem ser escritas na forma de $\mathrm{J}_{1}=\mathrm{L}_{11} \mathrm{X}_{1}+$ $\mathrm{L}_{12} \mathrm{X}_{2}$ e $\mathrm{J}_{2}=\mathrm{L}_{21} \mathrm{X}_{1}+\mathrm{L}_{22} \mathrm{X}_{2}$ onde $\mathrm{X}_{1}$ é o gradiente de temperatura e $\mathrm{X}_{2}$ é a força que determina a difusão e $\mathrm{L}_{\mathrm{t}}$ são os coeficientes fenomenológicos em que $\mathrm{L}_{\mathrm{in}}$ são os coeficientes directos que traduzem a dependência do fluxo em causa relativamente à força associada ao gradiente de um factor relacionado com o constituinte do fluxo, e $\mathrm{L}_{i j}$, os coeficientes de «arrasto» que traduzem a dependência do fluxo relativamente a gradientes não directamente relacionados com o constituinte do fluxo. As relaçôes de reciprocidade de Onsager estabelecem que $\mathrm{L}_{\mathrm{ij}}=\mathrm{L}_{\mathrm{j}}$ (cf. v.g. W. J. Moore, Physical Chemistry, Longman, Londres, 1974, pp. 359-361).

[5] L. Prigogine e I. Stengers, O. Cit., pg. 216.

[6] (a) G. Nicolis and I. Prigogine, Self-Organization in non-equilibrium systems, Wiley-Interscience, New York, 1977; (b) I. Prigogine, Physique, Temps et Devenir, Masson, Paris, 1980; (c) I. Prigogine, Between Time and Eternity: Nehru and Einstein, Jawaharlal Nehru Lecture, 1983; (d) A. Jacquard, A Herança da Liberdade, Publ. D. Quixote, Col. Ciência Nova, 7, Lisboa, 1988; (e) Francis Crick, Vida, o mistério da sua origem e natureza, Ed. Gradiva, Col. Ciência Aberta, 23, Lisboa, 1988; (f) P. T. Landsberg (ed.), The Enigma of Time, Adam Hilger, Bristol, 1982.

[7] I. Prigogine e I. Stengers, O. Cit., pg. 438; D. K. Kondepudi and I. Prigogine, Physica, 107A, 1981, pp. 1-24; D. K. Kondepudi, Physica, 115A, 1982, pp. 552-566; R. Lefever and W. Horsthemke, Noise-Induced Transitions Theory and Applications to Physics, Chemistry and Biology, Springer-Verlag, Berlim, 1984.

[8] (a) Jean Starobinski, Ordre et Désordre, XXIX Encontro Internacional de Genebra, Set, 1983; (b) Edgar Morin, Ciência com Consciência, Publ. Europa-América, Col. Biblioteca Universitária, 32, Lisboa, pp. 71-95; (c) I. Prigogine and I. Stengers, Order out of Chaos: Man's New Dialogue with Nature, Heineman, Londres, 1984.

[9] J. Monod, Acaso e Necessidade, Publ. Europa-América, Lisboa, 1972. [10] I. Prigogine, Entrevista com José Manuel Fernandes in ExpressoRevista, 5, Nov. 1988, pp. 26R-27R.

[11] I. Prigogine e I. Stengers, A Nova Aliança, pg. 373.

[12] Santo Agostinho, Confissōes, Liv. XI, 14.

[13] (a) Karl R. Popper, The Arrow of Time, Nature, 1956, pg. 538; (b) R. Schelegel, Irreversibility and Mechanics, Nature, 178, 1956, pg. 381; (c) E. L. Hill and A. Gunbaun, Irreversible Processes in Physical Theory, Nature, 179, 1957, pg. 1296; (d) R. C. L. Bosworth, Irreversible Processes in Physical Theory, Nature, 181, 1958, pg. 402; (e) Karl R. Popper, Time's Arrow and Entropy, Nature, 207, 1965, pg. 233; (f) W. Buchel, Entropy and Information in the Universe, Nature, 213, 1967, pg. 319; V. Satchuthananthale and R. C. Cooke, Negentropy, information and the Feeding of Organisms, Nature, 213, 1967, pg. 952.

[14] Karl R. Popper, Universo Aberto, Argumentos a favor do Indeterminismo, Publ. D. Quixote, Col. Opus, 6, Lisboa, 1988, pp. 69ss.

[15] S. W. Hawking, Breve História do Tempo, Do Big-Bang aos Buracos Negros, Ed. Gradiva, Col. Ciência Aberta, 27, Lisboa, 1988, pg. 198; S. W. Hawking and G. F. R. Ellis, The Large Scale Structure of Space-Time, Cambridge University Press, Cambridge, 1973.

[16] I. Prigogine e I. Stengers, A Nova Aliança, pg. 236.

[17] Ibidem, pp. 268ss.

[18] G. Gale, The Anthropic Principle in Scientific American, vol. 245, 1981, pp. 114ss; Paul Davis, Other Worlds, Space, Superspace and the Quantum Universe, Ed. J. M. Dent and Sons, Londres, 1981, pp. 142-161. 


\section{Convite à Reflexão ...}

\section{Resolver o passado científico}

Em quase todos os domínios, especialmente naqueles que, no século XX, foram motores da cultura científica e do progresso tecnológico, a ciência moderna não encontra em Portugal um passado - próximo ou remoto - onde se filie; do mesmo modo, não herdou desse passado escola de formação ou horizonte de valores sobre os quais possa fundar a construção de uma nova comunidade científica ou de uma presença nova e actuante da ciência na cultura do país.

Se uma frase brutal pode caracterizar a história das ciências modernas, devemos afirmar que estivemos, acima de tudo, num vasto e continuado estado de ignorância. Santa ignorância!

Está por fazer o diagnóstico da histórica ignorância do país. Em fins do século XVIII - isto é, há duzentos anos -, o matemático José Anastácio da Cunha traçava, nas Notícias Literárias de Portugal, o retrato impiedoso e amargo da ignorância pátria nos diferentes ramos do saber. A lição dessas palavras continua hoje por assimilar na cultura portuguesa, que tende mais à invenção glorificadora de um passado mítico que ao inventário das carências estruturais, possibilitador de acções mais coerentes e mais sólidas na construção do futuro.

Estou convencido de que a erradicação dessa espécie de cretinismo nacional que consiste em inventar, para a pequenez científica presente, um álibi que a reduza ao lugar de circunstância passageira, por exaltação do período - suposto de grande ciência - dos descobrimentos portugueses, é uma primeira medida profiláctica indispensável à construção de actividades científicas modernas e de qualidade.

Duas razões existem para pensar assim.

A primeira, mostrando como a incapacidade de fundar, em Portugal, actividades científicas modernas, nos séculos XVI e XVII, é um fenómeno de compreensão importante para o futuro, pois revelador de condições sociais e culturais, e de abertura intelectual ao exterior, necessárias ao desenvolvimento científico.

A segunda, lembrando que a invenção de um passado científico português, miraculoso e sem deixar rasto, quase secreto, tende a alimentar a perniciosa ideia de que as ciências se não enraízam no social, na educação e nos hábitos, antes surgem armadas nas cabeças de henriquinos governantes.

A primeira razão para afrontar o mito da ciência portuguesa perdida é pois de crítica ao negativismo e à ideia de predestinação nacional. A segunda razão é, essencialmente, anti-sebastianista.
[...] Devo a Eduardo Lourenço, a quem agradeço, neste ponto, a lição relativa ao debate que, em Espanha, teve por emblema a "polémica da ciência espanhola», nos séculos XVIII, XIX e no início do século XX, precisamente em torno do diagnóstico das causas do atraso científico de Espanha e da questão, tão viva aí como entre nós, do significado para o presente da actividade técnica e científica que acompanhou a expansão marítima. Neste ponto, creio que o desenvolvimento científico, quer em Portugal quer em Espanha, deverá exorcisar fantasmas idênticos e enfrentar, com lucidez, a análise histórica do processo que manteve afastados da Europa culta, durante vários séculos, raros e pouco continuados assomos de conhecimento e instrução científica. O trabalho comum, sobre esta temática, de instituições e pessoas dos dois países será, sem dúvida, enriquecedor para ambos e de interesse público geral, fora dos círculos de especialistas. A história de José Anastácio da Cunha ilumina, com a sua luz fria, as tentativas portuguesas de saída do atraso e do isolamento científico e permite marcar, simbolicamente, a distância a percorrer.

Recordem-se, sem nenhum comprazimento negativista, mas numa óptica de construção do futuro, célebres passagens cuja consciência crítica e vontade de mudança deveria impregnar a formação das novas gerações:

[...] «Não é ao clima, nem à atmosfera, nem ao solo, nem aos nossos órgãos, nem, enfim, às causas físicas que devem ser imputadas culpas - restam as morais, a cuja investigação e análise me esquivarei. Não obstante, não nos podemos coibir de nos queixar sobretudo dos nossos jesuítas, de D. Sebastião, do cardeal-rei e dos Espanhóis.

«Antes desse tempo desditoso já tínhamos logrado alcançar, ainda que com o auxílio dos estrangeiros, e imitando-os, lugar honroso na república das letras. Os nossos sábios eram conhecidos, respeitados, solicitados pelo estrangeiro. [...] A erudição difundia-se no Reino, e cada vez se difundia mais. [...] Já não era lícito duvidar que fôssemos dotados de todas as virtualidades necessárias ao estudo das ciências e das artes, e íamos provavelmente enriquecê-las também com os nossos descobrimentos $[\ldots]$

«Mas aniquilou-se a matemática, baniram-se as belasartes, alijaram-se várias personalidades de mérito: o desalento e a miséria arrebataram-nos Camões. [...] O Céu vingou-o: com efeito, a partir de então, mais não temos feito que estagnar na ingorância e suscitar o desprezo dos estrangeiros.»

J. M. Gago, «Manifesto para a Ciência em Portugal» 